\title{
RESENHAS
}

REVIEWS

\section{JUST HEALTH: MEETING HEALTH NEEDS FAIRLY}

\author{
By Norman Daniels
}

Cambridge: Cambridge University Press, 2008

Adriana Lee Benedict ${ }^{* *)}$

Em Just Health Care(1), Norman Daniels constrói uma coerente teoria sobre justiça na atenção à saúde baseada nos dois princípios de "justiça como equidade" do filósofo político americano John Rawls. Na condição de características fundamentais do igualitarismo liberal, esses dois princípios são o princípio da liberdade - que requer que todos os indivíduos tenham o direito às mesmas liberdades básicas, tais como participação política e liberdade de expressão - e o princípio da diferença - o qual declara que desigualdades sociais e econômicas são permitidas somente à medida em que promovam o bem-estar dos menos favorecidos, e que eles promovam a justa igualdade de oportunidade de acordo com princípios igualitários ${ }^{(2)}$.

Um quarto de século mais tarde, em Just Health: Meeting Health Needs Fairly(3), Daniels expande as fundações éticas estabelecidas em Just Health Care para suplementar o limitado escopo dos princípios de justiça com a proposta de um sistema de procedimento justo. Daniels substitui o que ele chamou de "Questão Fundamental" - o que devemos ao outro em saúde como uma questão de justiça - por três "Questões Focais" com o intuito de trazer soluções concretas ao problema da justiça distributiva em saúde e ajudar a identificar quais questões continuam não resolvidas sem um processo justo. Essas questões perguntam: (1) A saúde (e consequentemente o cuidado à saúde) possui uma especial importância moral?; (2) Quando as desigualdades em saúde são injustas?; (3) Como podemos satisfazer as necessidades em saúde de uma maneira justa dada a escassez de recursos?

(*) Mestranda em Saúde Pública na Harvard School of Public Health.

Recebido em 22.02.10

(1) DANIELS, N. Just health care. Cambridge: Cambridge University Press, 1985.

(2) RAWLS, J. A theory of justice. Cambridge: Harvard University Press, 1971.

(3) DANIELS, N. Just health: meeting health needs fairly. Cambridge: Cambridge University Press, 2008. 
Suas respostas a essas questões são filosoficamente e empiricamente elegantes, criando uma integrada teoria de justiça e saúde que enfatiza o papel essencial dos determinantes sociais da saúde. Ao mesmo tempo, essas respostas levantam uma série de outras questões que não só continuam não respondidas, mas que também são problemáticas para sua teoria.

A resposta de Daniels para sua primeira Questão Focal é uma extensão da própria perspectiva de Rawls sobre a satisfação das necessidades em saúde:

Provisões para cuidado à saúde, assim como bens primários em geral, devem satisfazer necessidades e exigências dos cidadãos como livres e iguais. Tais cuidados incluem-se entre os meios gerais necessários para garantir justa igualdade de oportunidade e nossa capacidade de usufruir de nossas liberdades e direitos básicos e, dessa forma, poder ser um membro normal e plenamente cooperativo da sociedade pelo período completo de nossas vidas ${ }^{(4)}$ (p. 63).

Daniels estende essa ideia ao adicionar que, como saúde e oportunidade estão diretamente relacionadas, satisfazer necessidades de saúde promove igualdade de oportunidade e, consequentemente, é de especial importância moral devido à validade das teorias que preservam a igualdade de oportunidade.

Isso estabelece o patamar para sua resposta à segunda Questão Focal, o qual identifica quando as desigualdades em saúde são de fato injustas e que, portanto, devem ser corrigidas pela sociedade. Reconhecendo as lacunas deixadas pela sua estrutura filosófica, a resposta de Daniels a sua terceira Questão Focal apresenta uma estrutura teórica útil para ajudar sociedades a lidarem com as três "questões não resolvidas de racionamento"(5).

Chamado de controle pela razoabilidade, essa estrutura teórica faz uso do processo justo para preencher as lacunas deixadas pelo princípio de justiça devido à realidade que pessoas razoáveis discordarão sobre o relativo peso de demandas conflitantes em saúde. Controle por razoabilidade parece ser a resposta usada por Daniels para enfrentar a quarta questão não resolvida de racionamento - o problema da democracia, o qual questiona "quanto peso deve ser dado a julgamentos baseados teoricamente ou na intuição em oposição a preferências expressas"(6). O processo deliberativo de controle por razoabilidade oferece uma solução parcial ao problema ao invocar condições de publicidade, relevância, instâncias de revisão e recurso, e regulação, para tomada de decisão que seja convincente ao desafio do desacordo razoável entre pessoas imparciais.

(4) RAWLS, J. op. cit.

(5) Daniels descreve esses problemas como o problema de agregação (quando a soma de modestos benefícios a um número maior de pessoas deveria se sobrepor a benefícios significativos a um número menor de pessoas?); as prioridades ou o problema "maximin" (quanta prioridade deve ser dada para tratar os pacientes mais doentes ou desabilitados?); e o problema da justa oportunidade/ melhor resultado (quanto deveríamos favorecer a produção do melhor resultado?).

(6) DANIELS, N. Four unsolved rationing problems: a challenge. The Hastings Center Report, n. 24, p. 27-29, 1994. 
As duas últimas condições para o controle pela razoabilidade (instâncias de revisão e recurso, e regulação) dependem do primeiro princípio de "justiça como equidade". Eles dependem de participação política e liberdade de expressão, e essas condições não podem existir no vácuo sem o cumprimento do princípio de liberdade de Rawls. É problemático o fato de Just Health não lidar com essa questão porque Daniels pretende que sua teoria seja estendida a países em desenvolvimento, muitos dos quais ainda precisam atingir os dois primeiros princípios de "justiça como equidade". Um exemplo que se sobressai, particularmente, é o estudo do caso do envelhecimento intergeracional na China. Daniels usa esse caso para ilustrar a necessidade de controle pela razoabilidade para preencher as lacunas deixadas pela sua "Prudential Lifespan Account". Contudo, ao fazer isso, Daniels não trata das condições proibitivas de liberdade na China (um país que ainda está para ratificar a Convenção Internacional sobre Direitos Civis e Políticos), e, consequentemente, da medida em que o controle pela razoabilidade pode efetivamente funcionar. A análise de Daniels do projeto $3 \times 5$ é igualmente fraca como exemplo, na medida em que se admite que não só problemas não resolvidos de racionamento persistem em determinar padrões globais para distribuição nacional de antirretrovirais, mas também que o processo justo pode ser aplicado na ausência de - e consequentemente não pressupõe - princípios de justiça como equidade. Enquanto esse argumento puder ser persuasivamente feito, ele enfraquece o argumento de Daniels, de acordo com o qual princípios de justiça precedem o processo justo.

Além do mais, embora as quatro condições para o processo de controle pela razoabilidade são caracterizadas por um pragmatismo suavizado, esse não é o caso da elaboração daquilo que é necessário para preencher a exigência primária do tomador de decisão imparcial. Usando uma analogia com o estabelecimento de decisões para um jogo de futebol, Daniels explica que os principais atores na implementação do controle por razoabilidade devem ser pessoas que:

buscarão razões ("regras") que eles possam aceitar como relevantes para suprir as necessidades de saúde de uma maneira justa ... [que] moldem uma concepção do bem comum que é o objetivo da cooperação dentro de planos, mesmo quando os planos são conflitantes (p. 118).

A analogia é precipitada: enquanto decisões em saúde irão inevitavelmente afetar todos os membros da sociedade, incluindo aqueles que as estabeleceram - como se pode interpretar da alegação de Daniels de que "Toda (comparativa) decisão deixará algumas pessoas em melhor situação que outras” (p. 126) — decisões sobre as regras do futebol podem emergir de uma perspectiva neutra porque elas provavelmente não serão estabelecidas por aqueles que jogam o esporte.

Cabimento da analogia à parte, Daniels não oferece um quadro teórico para identificar ou definir "imparcialidade". Desnecessariamente, isso deixa 
em aberto a possibilidade para um grupo de pessoas razoáveis que estão de acordo, mas cujas noções de bem comum não são apropriadas a ideais igualitários, a passarem no teste. Como Daniels apresenta a importância moral da saúde como sendo lexicalmente anterior a sua descrição de processo justo, dever-se-ia concluir que sua concepção de pessoas "imparciais" é intimamente derivada de sua descrição filosófica original. O papel previsto para esses indivíduos não é tão diferente daquele do indivíduo que participa da "posição original", um experimento lógico de Rawls e que é lexicamente anterior aos seus princípios de "justiça como equidade".

Como um meio para alcançar a mais justa distribuição de bens sociais primários, a "posição original" propõe que indivíduos façam suas decisões sob o "véu de ignorância", tornando-os não cientes de sua classe, status socioeconômico, ou talentos ${ }^{(7)}$. Presumidamente, essa é a única forma de garantir uma tomada de decisão justa porque ele resulta em um indivíduo razoável dando valor ao leque de bens primários e oportunidades que maximizam o bem-estar. Nesta perspectiva, se o véu de ignorância é a necessária pré-condição para se chegar aos princípios de justiça como equidade propostos por Rawls, e esses princípios fornecem o ponto de partida para Just Health, não deveria a perspectiva "imparcial" necessária para o controle pela razoabilidade ser simpático também à posição original? $\mathrm{Na}$ ausência de uma racionalidade imparcial, segue obscuro em que medida nós podemos realmente confiar que um interessado no processo de tomada de decisão esteja agindo razoavelmente.

Just Health dedica um capítulo inteiro para tratar sobre a relevância do estabelecimento de prioridades em direitos humanos, especialmente em traçar uma análise mais robusta da sua progressiva realização. A retórica de Daniels e seus exemplos claramente ilustram o valor agregado pelo controle pela razoabilidade para a agenda de direitos humanos, o qual é frequentemente omisso em questões específicas de alocação de recursos, especialmente sobre as questões não resolvidas de racionamento. Entretanto, o foco de Daniels em direitos humanos não vai mais além para discutir se os princípios de direitos humanos podem também lançar luz sobre os problemas não resolvidos de racionamento que oscilam entre princípios de justiça e justo processo.

Considerando o problema das prioridades, por exemplo, o princípio de direitos humanos de focar nos grupos mais vulneráveis (UN CESCR General Comment 14, para. 65), enquanto Daniels está correto em explicar que dar prioridade àqueles em pior condição definidos como "os mais doentes" levaria inevitavelmente a insustentáveis insuficiências (e consequentemente solapar a abordagem igualitária), isso não é necessariamente verdade se dermos tal

(7) RAWLS, J. op. cit. 
prioridade aos menos favorecidos definidos como aqueles indivíduos mais vulneráveis a violações de direitos e desigualdades tanto em condições quanto em acesso aos recursos. Não é necessariamente verdade que nenhuma estrutura teórica ética não possa tratar da questão de quem são os menos favorecidos. Reconsiderando a questão da prioridade aos menos favorecidos como uma de prioridade aos mais vulneráveis, é tão informativo quanto aplicar o controle de razoabilidade à progressiva realização. Além do mais, tal desigualdade de prioridade não somente é permitido de acordo com o princípio de diferença de Rawls, como também é justificado para além de questões de justiça como equidade.

Quando damos prioridade aos mais vulneráveis, isso ocorre não só porque tal desigualdade é entendida como uma questão de justiça, mas também porque há um virtual acordo universal insculpido nos tratados internacionais de direitos humanos (para não mencionar a psicologia moral e outros paradigmas analíticos) que aponta em direção a uma propensão a ajudar primeiro aqueles que são menos capazes de se ajudarem. Não é improvável que isso possa decorrer de uma rejeição intuitiva das teses que recursos são permanentemente escassos, como sugerida por Frances Kamm - a simples noção que "salvando os mais doentes primeiro significa que há mais tempo para salvar os menos doentes depois" (p. 277).

É louvável que Daniels termine sua análise com o desafio de estender os princípios de Just Health a questões de globais de saúde. Na ausência de uma arquitetura institucional com a capacidade de se encarregar da justiça procedimental de acordo com as condições de controle por razoabilidade, nós somos deixados com o desafio momentâneo de responder às Questões Focais além do nível nacional. Enquanto os princípios de justiça como equidade permitem uma robusta e lógica abordagem à alocação de recursos de saúde, sua pressuposição cria um desafio para qualquer extensão teórica dependente de sua efetivação. As condições ao redor do mundo variam tanto que qualquer processo uniforme para uma justa distribuição iria inevitavelmente (a) exigir condições de democracia e (b) ser incongruente na grande maioria dos contextos; e Just Health é problematicamente silente sobre o que acontece à justiça procedimental quando condições preliminares de justiça não estão satisfeitas. Como Daniels está focado em tratar de expandir o domínio da ética em âmbito populacional, nós teremos que procurar em outros lugares como lidar com seu desafio - talvez mesmo nos paradigmas analíticos (como os direitos humanos) desdenhados como "onde não começar" no primeiro capítulo (p. 6).

\section{REFERÊNCIAS BIBLIOGRÁFICAS}

DANIELS, N. Four unsolved rationing problems: a challenge. The Hasting Center Report, n. 24, p. 27-29, 1994.

Just health care. Cambridge: Cambridge University Press, 1985. 
Just health: meeting health needs fairly. Cambridge: Cambridge University Press, 2008.

RAWLS, J. A theory of justice. Cambridge: Harvard University Press, 1971. 